\title{
RIGHT CORONARY ARTERY FROM AORTO-LEFT VENTRICULAR TUNNEL: CASE REPORT OF A NEW SURGICAL APPROACH
}

\author{
Jürg Grünenfelder, MD, Gregor Zünd, MD, René Prêtre, MD, Jürg Schmidli, MD, Paul R. Vogt, MD, and \\ Marko I. Turina, MD, Zürich, Switzerland
}

Aorto-left ventricular tunnel is a rare congenital anomaly, which was first described by Edwards ${ }^{1}$ in 1961. The tunnel is a communication between the ascending aorta and the left ventricle. The right coronary artery (RCA) usually originates from the lateral wall of the aorta with a separate ostium next to the opening of the tunnel. Herein we report a case of anomalous RCA arising from the aorto-left ventricular tunnel itself. This rare anomaly, including its physiology and its surgical options, is discussed.

A 14-month-old baby boy was admitted for a work-up of a heart murmur known since birth. Echocardiography demonstrated a normal aortic valve without regurgitation and preserved left ventricular function. There was an aneurysmatically dilated communication anterior and to the right of the aorta between the ascending aorta and left ventricle bypassing the aortic valve. The RCA could not be visualized. Cardiac catheterization revealed a runoff of contrast material from the ascending aorta through a tunnel into the left ventricular outflow tract (LVOT). The opening of the tunnel was located in the anterior aspect of the ascending aorta above the right coronary sinus (Fig. 1). The ostium was $4 \mathrm{~mm}$ in diameter and the middle part of the tunnel was enlarged up to $11 \mathrm{~mm}$. The ventricular ostium in the LVOT was $8 \mathrm{~mm}$ in maximal diameter and was located right below the aortic valve in the conal septum. A selective injection of the tunnel showed an RCA arising from the dilated middle part of the tunnel with a large collateral vessel from the left anterior descending artery (Fig. 2, $A$ and $B$ ).

The operation was performed with cardiopulmonary bypass and moderate hypothermia $\left(26^{\circ} \mathrm{C}\right)$. Myocardial protection was achieved by antegrade and retrograde cold blood cardioplegia. After the aorta was crossclamped, the dilated tunnel was incised longitudinally and the ostium of the RCA was found in the lateral wall, approximately $3 \mathrm{~cm}$ distal to the aorta. Two additional openings were clearly identified, one in the ascending aorta and the other in the LVOT, anterior to the right fibrous trigone of the heart. Both openings were closed with a single patch of autolo-

From the Clinic of Cardiovascular Surgery, University Hospital, Zürich, Switzerland.

Received for publication Feb. 27, 1998; accepted for publication March 8, 1998.

Address for reprints: Jürg Grünenfelder, MD, Clinic of Cardiovascular Surgery, University Hospital, Rämistrasse 100, 8091 Zürich, Switzerland.

J Thorac Cardiovasc Surg 1998;116:363-5

Copyright (c) 1998 by Mosby, Inc.

$0022-5223 / 98 \$ 5.00+0 \quad \mathbf{1 2 / 5 4} / \mathbf{9 0 1 8 7}$

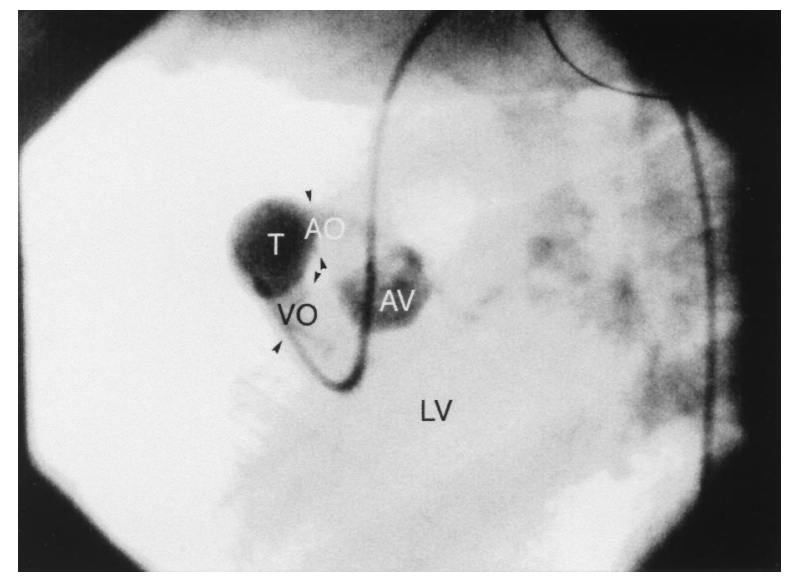

Fig. 1. Injection of the tunnel from the left ventricle in a left anterior oblique projection. $A O$, Aortic opening; $A V$, aortic valve; $T$, tunnel; $V O$, ventricular opening.

gous tissue tailored from the redundant wall of the tunnel to prevent any distortion of the right sinus of Valsalva. The RCA was excised from the tunnel wall and reimplanted into the aorta above the sinotubular junction with a resorbable running suture. The postoperative course was uneventful, and a follow-up transthoracic echocardiogram demonstrated a securely closed communication without any aortic valve incompetence.

Discussion. An RCA arising from an aorto-left ventricular tunnel is a rare anomaly, very few cases having been reported in the world literature. ${ }^{2-4}$ The case presented here firmly proposes the theory of Levy and associates ${ }^{5}$ that the defect may be an abnormal coronary artery and that its subsequent dilatation is acquired. However, there does not appear to be any correlation between the presence of such a dilatation and the age of the patient, because such cases have also been seen in newborn infants. It is possible, nonetheless, that part of the tunnel is a result of an anomalous formation of the RCA. The distal end of the tunnel is arterial in structure, with the part through the aortic wall being distinctly reminiscent of an intramural coronary artery. ${ }^{6}$ Morgan and Mazur ${ }^{2}$ considered that the communication between the aorta and the left ventricle might result from primary separation of the aortic anulus from the fibrous skeleton, whereas others believed on the basis of histologic evidence that the condition was related to Marfan's disease. Even a common origin with ruptured aneurysm of the sinus of Valsalva has been suggested. ${ }^{3}$ However, none of these theo- 

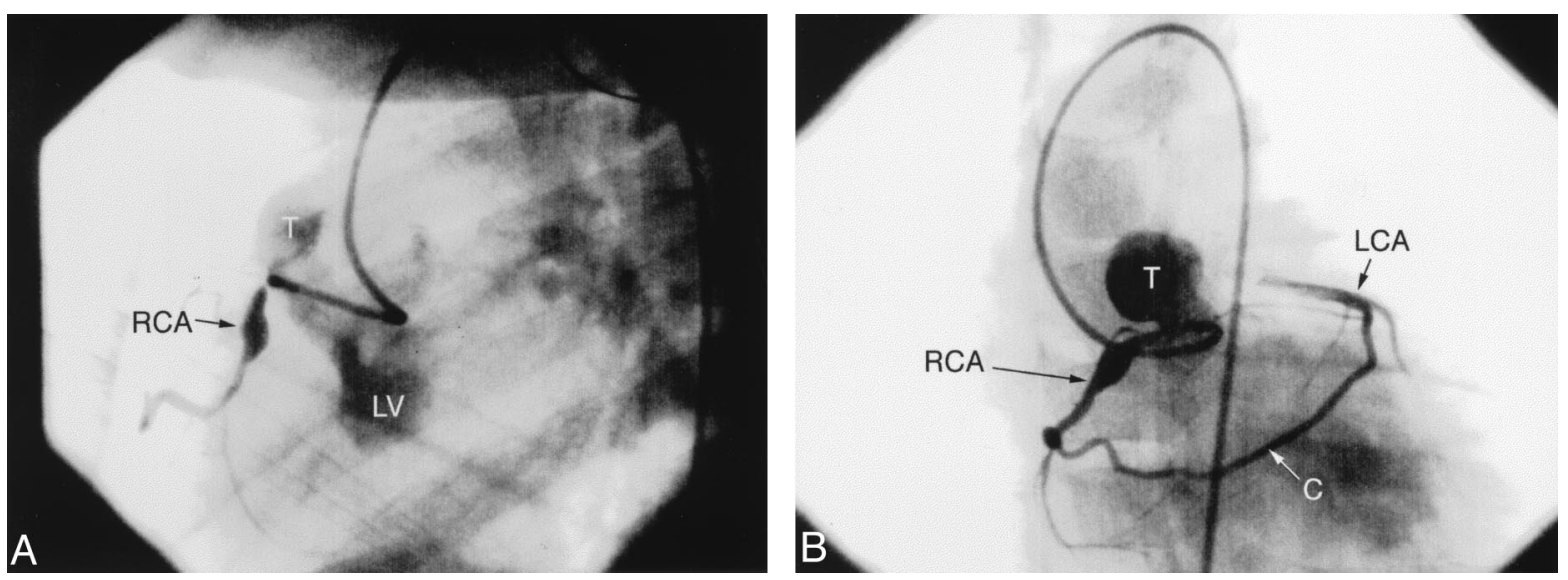

Fig. 2. A, Selective injection of the right coronary artery from the left ventricle through the tunnel in a left anterior oblique projection. B, Demonstration of the collateral vessel from the right coronary artery to the left anterior descending coronary artery in an anteroposterior projection. $C$, Collateral vessel; $R C A$, right coronary artery; $L V$, left ventricle; $L C A$, left coronary artery; $T$, tunnel.

A

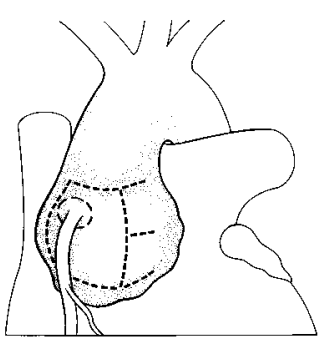

B

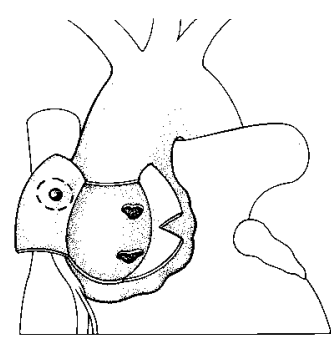

C

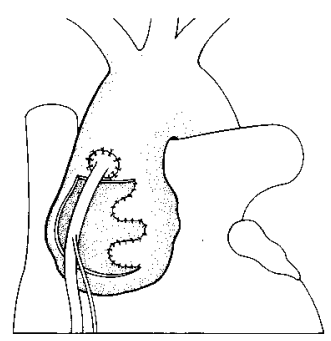

Fig. 3. A, Intraoperative presentation of the dilated aorto-left ventricular tunnel with the anomalous right coronary artery; dashed lines represent surgical access. B, View of opened tunnel displaying aortic and ventricular openings with right coronary artery ostium. C, Tunnel wall tailored to a single patch and sutured to the aortic and ventricular defects; right coronary artery button reanastomosed into aorta.

ries accounts for all patients and nothing has been proven yet.

Findings in aorto-left ventricular tunnel are very similar to those seen in aortic incompetence: systolic and diastolic murmurs, wide pulse pressures, and bounding pulses. Even severe congestive heart failure may be present. Congenital aortic regurgitation has to be ruled out, because associated aortic valve abnormalities may be present. Those may also be acquired from free aortic regurgitation stretching the cusps and the valve ring. In patients with aorto-left ventricular tunnel, closure of the tunnel in early childhood is advisable before severe dilatation of the anulus has caused secondary changes to the aortic valve.

Surgical experience with the treatment of an aorto-left ventricular tunnel is limited by the rarity of this anomaly, and the distinct anatomic setting of an RCA originating from the tunnel poses an additional challenge. Several surgical techniques for aorto-left ventricular tunnel repair have been reported in the literature, ${ }^{3-5,7,8}$ the standard technique being closure of the aortic and ventricular openings with two separate patches and transfer of the coronary artery. Sousa-Uva and associates ${ }^{8}$ instead reported two cases in which they only closed the ventricular opening to preserve coronary perfusion via the tunnel.

In this case we used a new approach in which the redundant tunnel wall was tailored in such a fashion as to close both the aortic and ventricular openings with a single patch. The anomalously originating RCA was excised from the tunnel wall and reanastomosed into the adjacent aorta (Fig. 3). To avoid persistence of a blind pouch causing turbulent flow, we believe that closure of both ends of the tunnel is mandatory to stabilize the aortic valve architecture.

The technique described herein offers a simple and efficient way of obliterating the communication without use of artificial material while preserving full integrity of the RCA and aortic valve. 


\section{REFERENCES}

1. Edwards JE. Atlas of acquired disease of the heart and great vessels. Vol. III. Philadelphia: WB Saunders; 1961. p. 1142.

2. Morgan RI, Mazur HJ. Congenital aneurysm of aortic root with fistula to the left ventricle: a case report with autopsy findings. Circulation 1963;28:589-94.

3. Spooner EW, Dunn JM, Behrendt DM. Aortico-left ventricular tunnel and sinus of Valsalva aneurysm. J Thorac Cardiovasc Surg 1978;75:232-6.

4. Horvath P, Balaji S, Skovranek S, Hucin B, de Leval MR, Stark J. Surgical treatment of aortico-left ventricular tunnel. Eur J Cardiothorac Surg 1991;5:113-7.
5. Levy MJ, Lillehei CW, Anderson RC, Amplatz K, Edwards JE. Aortico-left ventricular tunnel. Circulation 1963;27:841-53.

6. Gittenberger-de Groot AC, Sauer U, Quaegebeur J. Aortic intramural coronary artery in three hearts with transposition of the great arteries. J Thorac Cardiovasc Surg 1986;91:566-71.

7. Hovaguimian H, Cobanoglu A, Starr A. Aortico-left ventricular tunnel: a clinical review and new surgical classification. Ann Thorac Surg 1988;45:106-12.

8. Sousa-Uva M, Touchot A, Fermant L, et al. Aortico-left ventricular tunnel in fetuses and infants. Ann Thorac Surg 1996;61:1805-10. 